\title{
AN APPLICATION OF AHP IN CLIMATE CHANGE MITIGATION WITH ACQUIRING RENEWABLE ENERGY TECHNOLOGIES IN NEPAL
}

\begin{abstract}
Utilization of renewable energy resources not only generates useful energy but also aids in climate change mitigation. Energy development in Nepal has always been slow and the current generation only covers one third of the total demand. Although multiple renewable energy resources are available, due to the low economy all the types of energy systems cannot be developed together. The government seems to be perplexed in choosing the best among the alternatives as all the alternatives seems to be important and feasible. It becomes very important to prioritize them based on the peoples' need, resource availability, technical capability and environmental friendliness. Furthermore, it is also crucial to identify all the influencing actors that have major impacts on the development of energy systems in Nepal. This research identifies the most important actors, factors and alternatives which could be guidelines for the policy makers and researchers during the development of energy systems not only in Nepal but also applicable to other developing countries.
\end{abstract}

Keywords: AHP, climate change, renewable energy

\section{Introduction}

Though Nepal is not a major contributor to climate change, it cannot stay away from its consequences. Climate change mitigation can be achieved by transition from fossil fuel to renewable energy. Among several feasible renewable energy resources, the need is to identify the most efficient one based on the locality and climate change mitigation capability. Focusing on developing resources that the community is not responsive towards or has no contribution to climate change mitigation could not provide the optimal solution. Further, it should prove to be less costly for a developing country like Nepal. This research applies AHP in identifying renewable energy resources which are important in climate change mitigation and are considered to be user friendly by the community people in diverse terrains of the country.

\section{Rationality of the study}

Due to low economy, all the feasible options cannot be developed at once. The policy makers are finding it difficult to prioritize since multiple criteria exists. This study can assist by identifying the most important factors, actors and alternatives.

\section{Research question}

What should be the renewable energy development path for Nepal which could mitigate climate change and produce useful energy?

\section{Literature review}

Climate change mitigation can be achieved with the use of renewable energy sources (Abdulla et al., 2014 and Ibrahim, 2008) and the sustainable choice of selection requires consideration of various factors like: economic, environmental, social and technical (Klein et al., 2015 and Chatzimouratidis et al., 2009). AHP is capable of breaking complex problems into smaller parts which can be easily handled (Saaty, 2008). Chatzimouratidis et al. (2009) used AHP for assessment of power plants.

\section{Objectives}

To develop a model useful for policy makers regarding renewable energy selection to mitigate climate change in Nepal, and also applicable in the global scenario. 


\section{Research design}

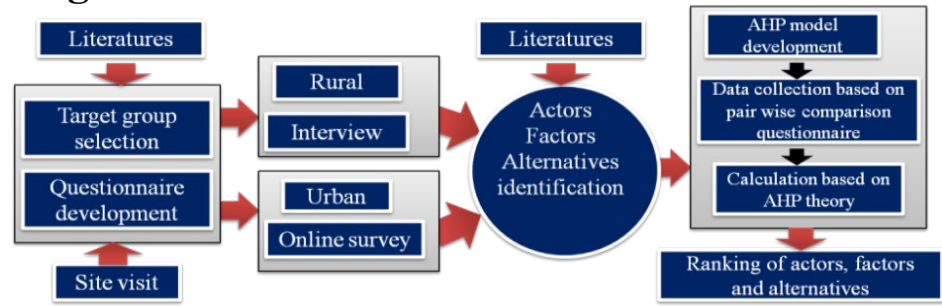

\section{Model Analysis}

The model developed has four levels with goal at level 1 followed by four factors at the level 2. Each factor has three sub-factors (SF) at level 3 and four alternatives at the level 4. Four major agents (actors) have been identified from first stage survey which is placed on either side of the hierarchy shown below.

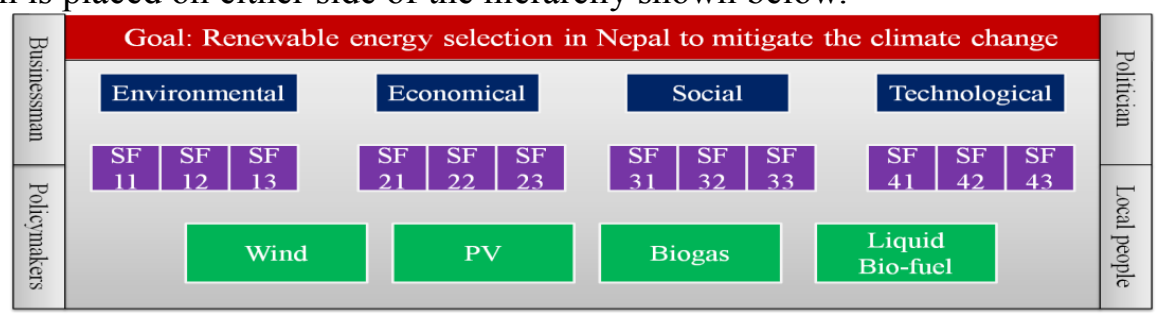

\section{Limitations}

There is no unanimity about the best method of combining the responses. The method used in this research relies on subjective judgments for the analysis. The result can be tilted towards the opinion of selected people. Maintaining consistency is a very critical factor for the members' views to be accurately reflected in the results.

\section{Conclusions}

This study is the first of its kind in climate change mitigation with renewable energy. Due to low economy, countries like Nepal need to prioritize the alternatives considering various subjective areas and incorporate the voice of economically weaker and marginalized groups, and this research can guide policy makers.

\section{References}

Abdullah, M. A. et al. (2014), Climate change mitigation with integration of renewable energy resources in the electricity grid of New South Wales, Australia, Renewable Energy, 66, 305-313.

Klein, S.J.W. et al. (2015), Comparing the sustainability of U.S. electricity options through multi- criteria decision analysis, Energy Policy, 79, 127-149.

Chatzimouratidis, A. I. et al. (2015), Technological, economic and sustainability evaluation of power plants using the Analytic Hierarchy Process , Energy Policy, 37, 778-787.

Ibrahim, Y. (2008), Global warming and renewable energy sources for sustainable development in Turkey, Renewable Energy, 33, 802.

Saaty, T. L. (2008), Decision making with the analytic hierarchy process. Int. J. Services Sciences, 1(1), 83-98. 